\title{
Partial molar pregnancy associated with a normal appearing foetus: a case report and review of the literature
}

\author{
Sujata Singh ${ }^{1}$, Sasmita Swain ${ }^{1}$, Lucy Das ${ }^{1}$, Pravat Chandra Das $^{2 *}$
}

\begin{abstract}
${ }^{1}$ Department of Obstetrics and Gynecology, S.C.B Medical College and Hospital, Cuttack, Odisha, India
${ }^{2}$ Community Health Centre, Biridi, Jagatshinghpur, Odisha, India
\end{abstract}

Received: 13 April 2017

Accepted: 08 May 2017

\author{
*Correspondence: \\ Dr. Pravat Chandra Das, \\ E-mail: preetadeep15@gmail.com
}

Copyright: (c) the author(s), publisher and licensee Medip Academy. This is an open-access article distributed under the terms of the Creative Commons Attribution Non-Commercial License, which permits unrestricted non-commercial use, distribution, and reproduction in any medium, provided the original work is properly cited.

\begin{abstract}
Partial molar pregnancy is a rare entity in which there is usually a triploid abnormal foetus associated with a large placenta with cystic changes. The incidence of a normal diploid foetus and a partial molar placenta is extremely rare. Here we report a case of partial molar pregnancy in which a normal appearing foetus with diploid karyotype coexist. In this case a $24 \mathrm{yr}$ old primigravida at 20 week 3days gestation presented with 3-4 episodes of vaginal bleeding and generalised swelling of body since one month. On evaluation she was found to have moderate anaemia, proteinuria, raised serum $\beta$ hcg and USG showed a single live foetus with thickened cystic placenta covering the internal os. After counselling patient was put up for hysterotomy. The product of conception and placenta were sent for histopathology and karyotyping which confirmed partial hydatidiform mole with trisomy 21 foetus. Patient had uneventful post op period and was followed up with serial $\beta$ hcg measurement which fell to undetectable levels within two months.
\end{abstract}

Keywords: $\beta$ hcg, Dizygotic karyotype, Normal foetus, Partial mole, Trisomy 21

\section{INTRODUCTION}

Gestational trophoblastic disease consists of a broad spectrum of conditions ranging from an uncomplicated partial hydatidiform molar pregnancy to stage IV choriocarcinoma with cerebral metastasis. Hydatidiform mole is characterized by abnormal fetoplacental development and trophoblastic hyperplasia, resulting from genetically abnormal conception when there is excessive paternally derived genetic material. It is classified into complete mole when there is total replacement of normal placenta by grossly dilated and hydropic villi in the absence of foetus and the incomplete or partial mole showing partial replacement with hydropic villi and visible abnormal foetal parts leading to termination of the pregnancy in first trimester. Foetus in such cases is rarely alive at the time of diagnosis and often shows gross congenital anomalies associated with triploidy and have a grave prognosis due to limited functional placenta and severe intrauterine foetal growth retardation. ${ }^{1}$

Partial molar pregnancy with coexistent live foetus as seen in our case is extremely rare excluding cases of multiple conceptions. Incidence of a normal foetus and partial molar placenta is 0.005 to $0.01 \%$ of all pregnancies. $^{2}$

\section{CASE REPORT}

A 24-year-old primigravida at 20 week 3 days of gestation presented with $3-4$ episodes of vaginal bleeding and generalised swelling of the body since one month.

On examination found to have anaemia (HB-7gm\%), generalised oedema, proteinuria, hyperproteinaemia, hypertension, raised serum $\beta$ HCG $(4,24,249 \mathrm{mIU} / \mathrm{ml})$, normal cardiovascular, renal, hepatic and thyroid 
function. P/A Fundal height was more than the period of amenorrhea. USG revealed single live foetus without any structural anomaly and biometry consistent with gestational age of 17 week 2 days. Estimated weight about 170gm (Small for date baby), placenta attached to posterior uterine wall covering internal os, thick $(82 \times 171 \mathrm{~mm})$ with radioluscent cyst (molar changes). No retro placental clot or separation seen. No evidence of separate normal placenta found. Both ovaries were enlarged $(52 \times 68 \mathrm{~mm}, 45 \times 58 \mathrm{~mm})$ with thecal lutein cyst. Patient was put on antihypertensive therapy. Severe preeclampsia persisted despite optimal therapy hence a decision to terminate the pregnancy was made. In view of placenta praevia hysterotomy was done and adequate blood transfusion was given.

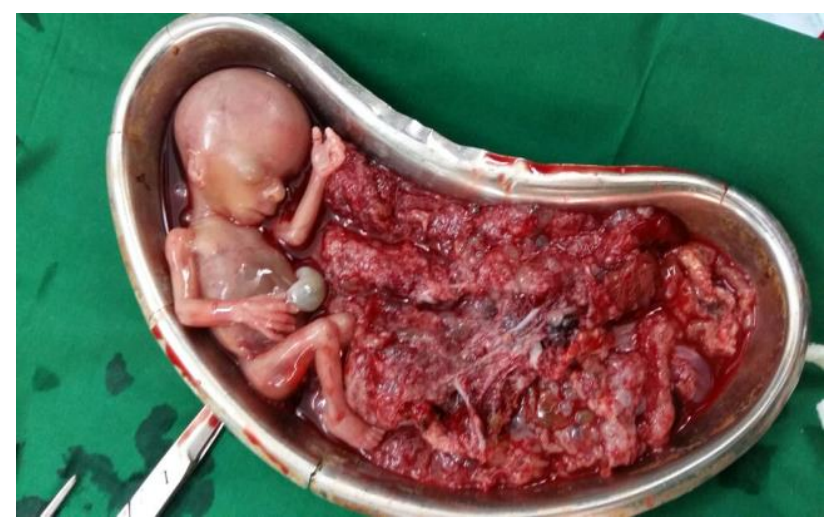

Figure 1: Foetus (approx. 200gm) and placenta (approx. 700gm) with multiple grape like vesicles.

An apparently normal live foetus (approx. 200gm) and placenta (approx. 700gm) with multiple grape like vesicles was evacuated and sent for karyotyping and histopathologic study respectively. Histopathology showed partial molar changes in placenta and karyotyping showed trisomy 21. Serial monitoring of serum $\beta$ hcg performed monthly for two month showed downward trend with a level of $0.57 \mathrm{mIU} / \mathrm{ml}$ after 2 months. She was advised barrier contraceptive to avoid pregnancy for at least one year

\section{DISCUSSION}

Partial molar pregnancy with coexistent live foetus as seen in our case is extremely rare excluding cases of multiple conceptions. Incidence of a normal foetus and partial molar placenta is 0.005 to $0.01 \%$ of all pregnancies. $^{2}$ It usually derives from dispermic fertilization of a haploid normal oocyte and produces a triploid set of chromosomes. ${ }^{3}$

Such association has been divided into three types. ${ }^{1}$

- The first and most common is a twin pregnancy with one normal foetus having a normal placenta and another complete mole.
- $\quad$ Second type is a twin pregnancy with normal foetus and placenta and another partial mole.

- The third and most uncommon occurrence is a singleton normal foetus with partial molar placenta.

Such a foetus should have a normal karyotype to survive. Placenta in a partial mole with foetus in a singleton pregnancy results from dispermy and has a triploid karyotype in most cases. ${ }^{4}$

Partial molar placenta with coexistent singleton normal foetus with normal karyotype has been reported only seventeen times in extensively searched medical literature. $^{5}$

In case of a singleton normal foetus with partial molar placenta, foetal survival depends upon several factors.

- $\quad$ Normal karyotype of the foetus (Sarno et al). ${ }^{6}$

- Smaller molar placenta compared to normal placenta (Jones, and Lauersen, Deaten et al). ${ }^{7}$

- The onset of molar degeneration and its speed of degeneration (Jones and Lauersan, Sarno et al). ${ }^{8}$

- Absence of anaemia occurring in the foetus (Crooij et al). ${ }^{9}$

- Absence of maternal complications such as preeclampsia, thyrotoxicosis and vaginal bleeding interrupting the pregnancy (Teng and Ballon). ${ }^{10}$

Szulman and Surti et al reported eight cases of partial mole coexisting with the foetus with normal karyotype after 15 gestational weeks, but only two of the infants survived. ${ }^{11}$

Parveen $\mathrm{Z}$ et al reported a partial hydatidiform mole along with term gestation ended in normal alive and healthy foetus. ${ }^{12}$

Pool R et al reported partial mole with coexistent live full term foetus. The pregnancy proceeded to term and ended in the spontaneous vaginal delivery of a normal baby. The placenta showed areas of macroscopic cystic degeneration with the histological features of hydatiform mole. $^{13}$

Kajal kiran Dhingra et al reported two cases of singleton pregnancy, in which focal placental molar change was deleted. However, the pregnancy ended in phenotypically normal term foetus. ${ }^{14}$

The problems in the management of molar pregnancy and a live foetus involve the risks of foetal abnormality, malignant trophoblastic change, and severe maternal complications such as preeclampsia, thyrotoxicosis, heavy bleeding, pregnancy failure, and preterm birth. Termination of pregnancy might be required due to these complications. Amniocentesis should be done for karyotyping. 
Our case had partial molar change with live foetus having complication of severe preeclampsia persisted despite optimal therapy hence a decision to terminate the pregnancy was made.

\section{CONCLUSION}

In conclusion, partial molar pregnancy with a coexisting live foetus, in addition to chromosomal evaluation and detailed ultrasound examination to exclude foetal abnormality before the decision to postpone intervention, prenatal consultation should include complete discussion of maternal and foetal risks, especially the possible requirement of chemotherapy or even hysterectomy. It is also necessary to have close follow-up and evaluation of the condition of the patient during prenatal and postnatal period.

\section{Funding: No funding sources}

Conflict of interest: None declared

Ethical approval: Not required

\section{REFERENCES}

1. Hsieh CC, Hsieh TT, Kuo DM, Lo LM, Hung TH. Delivery of a severely anaemic foetus after partial molar pregnancy: clinical and ultrasonographic findings. Hum Reprod. 1999;14:1122-6.

2. Suzuki M, Matsunobu A, Vakita K, Osanai K. Hydatidiform mole with surviving co-existent fetus. Ombt Gynecol. 1980;56:384-8.

3. Vaisbuch E, Ben-Arie A, Dgani R, Perlman S, Sokolovsky N, Hagay Z. Twin pregnancy consisting of a complete hydatidiform mole and co-existent fetus: report of two cases and review of literature. Gynecol Oncol. 2005;98:19-23.

4. Ohama K, Ueda K, Okamoto E, et al. Cytogenetic and clinicopathological studies of partial moles. Obstet Gynecol. 1986;68:259-66.

5. Guven ES, Ozturk N, Deveci S, Hizli D, Kandemir O, Dilbaz S. Partial molar pregnancy with coexisting fetus with diploid karyotype. J Matern Fetal Neonatal Med. 2007;20(2):175-181.

6. Sarno AP, Moorman AJ, Kalousek DK. Partial molar pregency with fetal survival: an unusual example of confined placental mosaicism. Obstet Gynecol. 1993;82:716-9.

7. Jones WB, Lauersen NH. Hydatidiform mole with coexistent fetus. Am J Obstet Gynecol. 1975;122:267-72.

8. Deaton JL, Hoffman JS, Saal H, et al. Molar pregnancy coexisting with a normal fetus: a case. Gynecol Oncol. 1989;32:394-7.

9. Crooiji MJ, Harten VD, Puyenbroek JJ. A partial hydatidi-form mole dispersed throughout the placenta, coexisting with a normal living fetus: case report. Br J Obstet Gynaecol. 1985;92:104-6.

10. Teng NNH, Ballon SC. Partial hydatidiform mole with diploid karyotype: report of three cases. Am J Obstet Gynecol. 1984;150:961-4.

11. Szulman, Surti. The syndrome of hydatiform mole (1) cytogenetic and morphological correlations. Am J Obstet Gynaecol. 1978;68:259-66.

12. Parveen Z, Bashir R, Jadoon T, Qayum L. Partial hydatidiform mole along with term gestation and alive baby. J Ayub Med Coll Abbottabad 2004;16(4):84-5.

13. Pool R, Lebethe SJ, Lancaster EJ, Partial hydatidiform mole with a coexistent live full term fetus: a case report. S Afr Med J. 1989;75(4):186-7.

14. Dhingra KK, Gupta P', Saroha V, Akhila L, Khurana N. Partial hydatidiform mole with a full term infant. Indian J Pathol Microbiol. 2009;52(4):590-1.

Cite this article as: Singh S, Swain S, Das L, Das PC. Partial molar pregnancy associated with a normal appearing foetus: a case report and review of the literature. Int J Reprod Contracept Obstet Gynecol 2017;6:2681-3. 